\title{
A Scoping Review of Police Involvement in School Crisis Response for Mental Health Emergencies
}

\author{
Kristen R. Choi ${ }^{1,2}\left(\right.$ Corey O'Malley $^{3,4} \cdot$ Roya ljadi-Maghsoodi ${ }^{3,4,5} \cdot$ Elyse Tascione $^{4} \cdot$ Eraka Bath $^{3,4} \cdot$ Bonnie T. Zima $^{3,4}$
}

Accepted: 22 September 2021 / Published online: 30 September 2021

(c) The Author(s) 2021

\begin{abstract}
The purpose of this scoping literature review was to examine research on police involvement in school mental health crisis response. The search was conducted in PsychInfo, PubMed, and ERIC and initially identified 315 articles. After applying inclusion/exclusion criteria, 47 articles remained. Detailed review and data extraction by three independent reviewers resulted in a final article count of nine. Three primary themes were identified across articles: (1) perceptions and consequences of law enforcement presence in schools; (2) the role of school-community partnerships in successful crisis response models; and (3) gaps in research and challenges of implementing and scaling existing models. Though in practice law enforcement officers are often involved in school mental health crisis response, there is limited empirical research supporting this approach. Our review did not return any randomized trials. In the absence of empirical evidence supporting the use of current models, there is a need for research on law enforcement involvement in school crisis response and, more broadly, community-partnered models of responding to student mental health needs.
\end{abstract}

Keywords School $\cdot$ Mental health crisis $\cdot$ Children and adolescents $\cdot$ Police $\cdot$ Law enforcement

\section{Introduction}

Schools are a central component of providing mental health services to children and youth and are often the de facto provider of care (Anderson-Butcher et al., 2006; Farmer et al., 2003). They are a trusted community institution that is often preferred by families for accessing support and resources, especially in regard to mental health (Albright et al., 2016).

Kristen R. Choi

krchoi@ucla.edu

1 School of Nursing, University of California, Los Angeles, Los Angeles, CA, USA

2 Fielding School of Public Health, University of California, Los Angeles, Los Angeles, CA, USA

3 Department of Psychiatry and Biobehavioral Sciences, David Geffen School of Medicine, University of California, Los Angeles, Los Angeles, CA, USA

4 Jane and Terry Semel Institute for Neuroscience and Human Behavior, University of California, Los Angeles, Los Angeles, CA, USA

5 HSR\&D Center for the Study of Healthcare Innovation, Implementation \& Policy, VA Greater Los Angeles Healthcare System, Los Angeles, CA, USA
Providing mental health services within schools, such as through school-based health centers, can also address the barriers to mental health care in the community, including transportation, cost, and accessibility (Albright et al., 2016; Amaral et al., 2011). Approximately 50\% of youth with mental health disorders who use mental health services do so in schools (Green et al., 2013). However, schools often do not have the capacity to comprehensively meet the mental, emotional, and social needs of all students-especially in under-resourced communities. National surveys indicate that in the USA, children 3 to 17 years of age experience anxiety (7.1\%), behavioral and conduct problems (7.4\%), and clinical depression (3.2\%), but $20-47 \%$ of these children do not receive treatment (Ghandour et al., 2019).

Adolescents, in particular, may benefit from school-based mental health services. An estimated $16 \%$ of female adolescents in the USA have symptoms of major depression, twice the prevalence rate among their male peers (Merikangas et al., 2010). Since 1999, adolescent suicide has increased $30 \%$ in the USA, underscoring the need for improved access to mental health care, including crisis interventions (Centers for Disease Control \& Prevention, 2021). In addition, mental health crises among teens frequently occur in schools. A school crisis is a situation involving unexpected disruption to 
a school's usual routine, psychological distress, and a need for immediate action to protect the safety of students, including those who are not experiencing the crisis (Kerr \& King, 2018). This definition captures a variety of school-level events including mental health crises (i.e., imminent danger of a child to themselves or others, or serious impairment in function from mental illness), but also spans events related to disruption, violence, and threats to student safety (e.g., school shooting and bombing). Nevertheless, school mental health crises, such as student suicidal ideation or attempts in school, require unique resources that schools are not always well-equipped to provide.

Schools face challenges in providing targeted and intensive mental health interventions when responding to mental health crises in schools (Werlen et al., 2020). As such, they historically may rely on law enforcement for responding to any crisis in school, whether it is a mental health crisis or other school disruption. Over the past two decades, police presence in schools has nearly doubled, due in part to rising concern about school violence and shootings. Approximately 58\% of public schools have embedded police officers, often called school resource officers, or other law enforcement presence (Diliberti et al., 2017). While the presence of law enforcement officers in schools is widespread, it is controversial and poorly studied. Law enforcement response to crises in schools can vary widely, ranging from physical presence only to verbal de-escalation to physical management of dangerous situations, as well as relationship-building with students, parents, and school staff for prevention of crises. There has been a rapid deterioration of confidence in law enforcement in recent years among adolescents (Fine et al., 2019). A recent systematic review indicated that there appears to be very little empirical research justifying the use of the school resource officer model, though this review was somewhat limited in scope by a focus on school resource officer use in the context of partnership with school nurses (Muller et al., 2021). However, schools continue to rely on law enforcement to respond to a myriad of student crises, including student violence and mental health emergencies.

Despite limited research, several bodies of research suggest reasons for concern with the role of police in school mental health and crisis response. Experts in child health have raised concern about how exposure to police violence affects developing children and what role police should play in childserving systems, including schools (Turner \& Beneke, 2019; Walters, 2020). There is substantial evidence that police contact is harmful to the mental health and educational achievement of youth, particularly boys and youth from racial/ethnic minority backgrounds (Del Toro et al., 2019; Gottlieb \&
Wilson, 2019; Jahn et al., 2020; Turney, 2020). One study found that police intrusiveness and contact at school were predictors of heightened emotional distress (Jackson et al., 2019). Research also indicates that Black and Latinx students, in particular, experience disproportionate and harsher discipline in schools, including police involvement, which has been linked to a school-to-prison pipeline that contributes to racialized mass incarceration in the United States (Barnes \& Motz, 2018; Rocque \& Paternoster, 2011; Welch \& Payne, 2010). Youth experiencing mental illness and mental health crisis, especially those from racial and ethnic minority backgrounds, are also disproportionately subjected to school discipline, arrest, and incarceration (Krezmien et al., 2006). Recent high-profile police killings of unarmed Black men, women, and youth have also heightened public debate about the role of law enforcement in communities and the efficacy of partnerships with law enforcement (Dreyer et al., 2020; Ehrenfeld \& Harris, 2020). For example, in February 2021, the Los Angeles Unified School District (LAUSD), the second largest school district in the country, approved a plan to reduce its police officer presence by a third, banned the use of pepper spray with students, and diverted funds to supporting Black student achievement (Gomez, 2021a). This action was in response to student activist and community member groups advocacy against the use of police force in schools-found to disproportionately affect Black students in LAUSD—with advocacy efforts increased in the wake of the murder of George Floyd and racial uprisings (Allen et al., 2018). Several other localities have also eliminated the use of police officers in schools or are exploring this option (Gomez, 2021b; Swartz, 2021).

Prior systematic reviews have examined the role of police involvement in crisis response in communities generally, but have focused on adults and not specifically examined police response to school mental health crises among youth (Engel et al., 2020; Seo et al., 2021). These reviews have been inconclusive and inconsistent about outcomes resulting from police crisis response, with a lack of rigorous evaluations of police response models and a lack of research generally on this issue. One recent review examined research on embedded school police and school nurse relationships and also found a lack of evaluation data, except for a small number of descriptive studies of school resource officers (Muller et al., 2021). This review focused primarily on school police models involving partnership with school nurses, and as such, evidence on law enforcement response to crises in schools more generally remains poorly understood. Given these gaps and recent discourse around the role of law enforcement, this scoping literature review critically examines research on police involvement in mental health crisis response in schools spanning kindergarten through twelfth grade (K12). 


\section{Methods}

\section{Design}

This scoping review used biomedical, education, and psychology databases to identify studies on the role of police in $\mathrm{K} 12$ school crisis response. A scoping review is a type of systematic review used to synthesize and map a broad range of evidence about an emerging or complex topic that is under-reviewed in the scientific literature (Arksey \& O'Malley, 2005; Pham et al., 2014). The steps of a scoping review are as follows (1) identify a research question, (2) identify relevant studies using a systematic search strategy, (3) select appropriate studies for review, (4) chart the data, and (5) summarize and report the results (Arksey \& O'Malley, 2005). We relied on the PRISMA Statement as a framework for reporting the methods of the systematic review (Moher et al., 2009) and an established scoping review methodology for reporting results (Arksey \& O'Malley, 2005). The role of police in school mental health crises is an emerging area of research, and there are insufficient high-quality studies on this topic for a systematic synthesis or meta-analysis. Given the current emerging state of the literature, we included a broad range of article types. In this review, we used the following definition of a school-based mental health crisis: at the school level, an unexpected disruption to a school's usual routine, psychological distress, and a need for immediate action to protect the safety of students, including those who are not experiencing the crisis (Kerr \& King, 2018). We defined an individual child mental health emergency as any situation involving immediate danger of a child to themselves or others, or grave disability as a result of a mental disorder that impairs the ability of a child to utilize elements of life that are essential to health, safety, and development (e.g., food, clothing, and shelter), and for the purposes of this review, which occurs at or is identified in a school setting (Children's Civil Commitment and Mental Health Treatment Act of 1988, 1988). This study was exempt for IRB review because it did not involve human subjects.

\section{Inclusion Criteria}

Articles were included in this review if they focused on mental health crisis response in a K12 school setting with children or adolescents, examined the role of police in such crises, were published in English, and were located in the USA. We allowed for inclusion of qualitative or quantitative articles, but required that articles were data-based to allow for synthesis of empirical evidence and to identify research gaps. Single-individual case studies, editorials, commentaries, and other literature reviews were excluded to narrow the focus of the review to school-level, empirical studies. We also excluded unpublished dissertations/ theses to ensure that studies were peer-reviewed. No time frame for inclusion was specified. These methodological and topical inclusion criteria were selected to capture a range of literature on police involvement in school crisis response in the USA, but also to assess the findings of and gaps in empirical evidence related to this topic.

\section{Search Strategy}

The literature search was conducted from November 2020 to January 2021 using three databases: PubMed (biomedical), ERIC (education), and PsychInfo (psychology). Search terms were (law enforcement $\mathrm{OR}$ police $\mathrm{OR}$ resource officer), school, and (crisis OR emergency OR mental health). Limits to the search were English language articles only, human subject articles only (i.e., exclude animal studies), and articles involving children or adolescents (under age 18 years).

Initially, 315 articles were identified across all three databases. The article titles and abstracts were reviewed by one reviewer to exclude articles unrelated to the population and topic of focus. This included studied of adults only, studies conducted outside the USA, college or university studies, articles unrelated to mental health crisis response (e.g., academic outcome studies), and articles that met methodological exclusion criteria described above (e.g., literature reviews, editorials, and single-person case studies). There were 47 articles remaining after this initial screen that were then evaluated by two independent reviewers for inclusion/ exclusion criteria. Duplicate articles were also removed at this stage. When there was disagreement about inclusion/ exclusion criteria, reviewers discussed the article against the inclusion/exclusion criteria until consensus was reached. A third reviewer was available in cases of disagreement between reviewers, though no such instances occurred. The final count was nine articles selected for data extraction (see Fig. 1).

\section{Data Extraction}

After consensus was reached about article inclusion, data extraction was performed manually by one research team member with experience in both mental health crisis response and research methods. The data extractor used an evidence table to organize information about article design, the study sample/setting, a description of the interventions or models of crisis response (if applicable), outcomes of police involvement or findings of the study, and study limitations. The evidence table was then independently reviewed by two additional reviewers against articles to ensure accuracy 


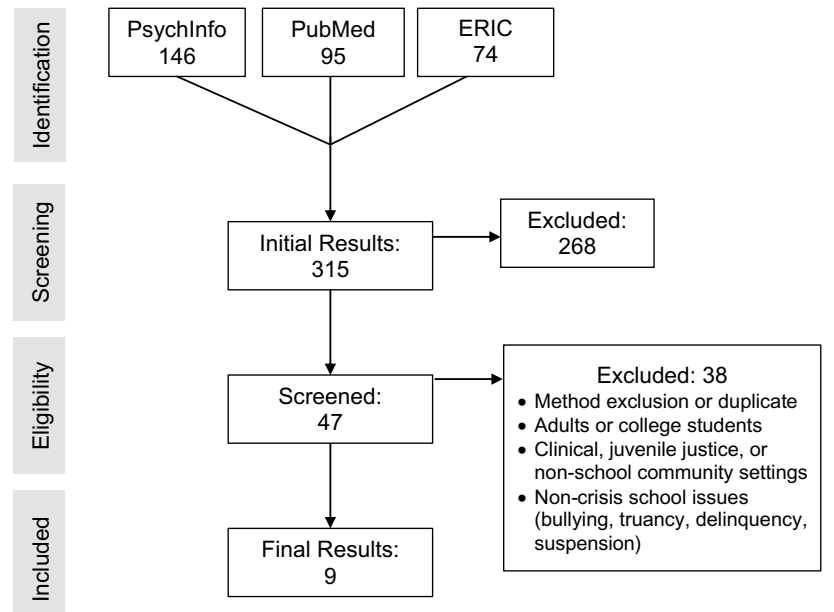

Fig. 1 Literature search flow diagram. This figure shows the literature search process and review of articles for inclusion/exclusion criteria in a systematic scoping review of police involvement in school mental health crisis response

of information and full capture of article findings. Then, we used this information to rate each study on the strength of evidence and evidence quality using the Oxford Centre for Evidence-Based Medicine (CEBM) Levels of Evidence (Oxford Centre for Evidence-Based Medicine, 2009). Two independent reviewers rated the study designs for their level of evidence. In the CEBM Levels of Evidence framework, the strength of the evidence for each study is determined by study design. Level 1 evidence includes systematic reviews of randomized controlled trials (Level 1a), randomized controlled trials (Level 1b), or all-or-nothing case series (Level 1c); Level 2 evidence includes systematic reviews of cohort and ecological studies (Level 2b), individual cohort studies (Level 2b), and ecological studies (Level 2c); Level 3 evidence includes systematic reviews of case control studies (Level 3a) or individual case control studies (Level 3b); Level 4 evidence includes case series studies; and Level 5 evidence includes expert opinion (though Level 5 evidence was not included in this review).

\section{Analysis}

All nine studies were included in the evidence synthesis. We tabulated methodologic characteristics of the nine studies (year published, level of evidence), assessing the percentage of evidence at each level of the CEBM Levels of Evidence framework and the range of publication years. Review findings were then analyzed using a charting process for scoping reviews (Arksey \& O'Malley, 2005). Charting involves sifting, sorting, and synthesizing study findings into key issues and themes, similar to a qualitative

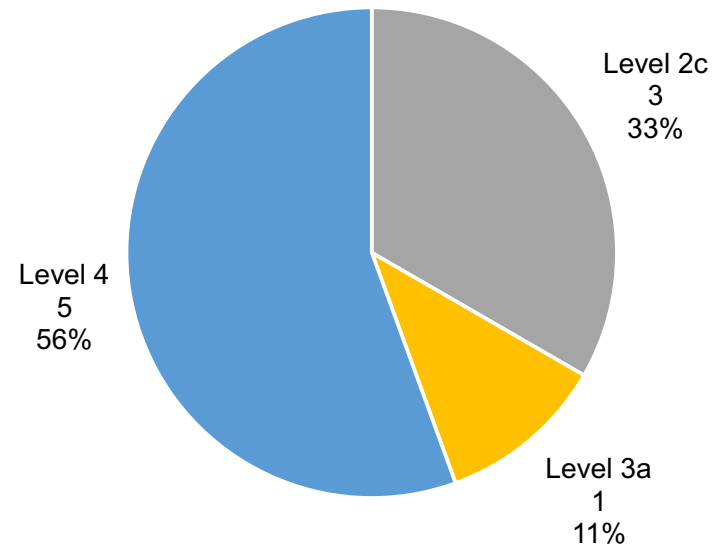

Fig. 2 Levels of evidence for sample. This figure shows levels of evidence for nine articles included in a systematic scoping review of police involvement in school mental health crisis response. Levels of evidence were identified from the Oxford Centre for Evidence-Based Medicine

thematic analysis or narrative review methodology and analogous to the statistical aggregation process used in a quantitative meta-analysis (Arksey \& O'Malley, 2005). Data were charted by two reviewers collaboratively, using a spreadsheet to simultaneously examine tabulated study characteristics, categorize study findings into themes, and identify research gaps across the nine studies.

\section{Results}

\section{Article Description}

The nine articles included in this review were published between 1993 and 2018. No randomized trials were identified. The studies were primarily ecological studies (Level $2 \mathrm{c}, 33 \%$ of articles) and school-level case studies or qualitative research (Level 4, 56\% of articles), as shown in Fig. 2. Several ecological studies relied on nationally representative survey data with large sample sizes, which was a strength. Although case reports and qualitative research articles had limited generalizability and, in some cases, were the oldest articles, they also provided detail about implementation of school-law enforcement partnerships for crisis response that survey research did not capture. There were three primary themes identified across results: (1) perceptions and consequences of law enforcement presence in schools; (2) the role of school-community partnerships in successful crisis response models; and (3) gaps in research and challenges of implementing and scaling existing models. 
Perceptions and Consequences of Law Enforcement in Schools

Certain groups of parents tended to have favorable perceptions of law enforcement presence in schools in relation to safety, while youth perceptions are unknown. In one survey, parents were supportive of school-law enforcement partnerships to promote safety and respond to violence in schools, and they also saw a relationship between improving mental health services generally and reducing school violence (Payton et al., 2017). This survey was with a primarily White (76\% of respondents), suburban (54\% of respondents), and male (56\% of respondents) sample and may not represent the views of all parents, particularly those from urban school districts or Black- or Hispanic-majority schools (Payton et al., 2017). Despite this perception of some parents, studies provided limited evidence for whether the presence of law enforcement in schools actually promotes safety. One study found that school security guards and strict enforcement of rules were associated with more incidents of school crime and disruption (Nickerson \& Martens, 2008). This finding was attributed to neighborhood and community factors more so than school factors, but raises questions about the effectiveness of school security measures (Nickerson \& Martens, 2008).

\section{Role of School-Community Partnerships in Successful Crisis Response Models}

There was a strong emphasis on the need for school-community partnerships and positive relationships between law enforcement officers and the school community in successful crisis response models (Daniels et al., 2007; Derzon et al., 2012; Heinen et al., 2006; James et al., 2011; Moriarty et al., 1993). The school-law enforcement partnership models for crisis response were primarily described in case reports (see Supplement 1 for descriptions of models). Models tended to involve (1) partnership- and relationship-building between law enforcement personnel, school staff, students, and parents; (2) development of criteria for law enforcement response and, in some cases, school-wide trainings; and (3) challenges and lessons learned from individual schools or districts implementing these models. These case reports did not involve rigorous evaluation of models, and "crisis response" was often applied broadly to incidents of violence as well as mental health crises. These methodological factors limit conclusions that can be drawn about model effectiveness. However, the relationships between school staff and law enforcement members were repeatedly emphasized as critical to success. In some cases, schools embedded a law enforcement officer in the school community, consistent with a school resource officer model (DeVane, 1996; James et al., 2011; Moriarty et al., 1993). These schools emphasized relationship-building by integrating school resource officers into education, promoting engagement with parents, interagency training, and having structured crisis response plans with clear, predefined roles for law enforcement staff and school staff (DeVane, 1996; Eklund et al., 2018; Heinen et al., 2006; James et al., 2011; Moriarty et al., 1993). Notably, models tended to designate authority and leadership roles to law enforcement in crisis response situations (James et al., 2011; Moriarty et al., 1993). One model specifically defined the law enforcement officer role as authoritative versus consultative depending on the kind of crisis, such as violence or suicide (Moriarty et al., 1993).

\section{Gaps in Research and Challenges of Implementing and Scaling Existing Models}

Perhaps the most notable finding from this review was the absence of rigorous research on law enforcement involvement in school mental health crisis response. The review did not identify any randomized controlled trials or quasiexperimental studies of law enforcement involvement models. Rather, there were large-scale surveys of police contact generally among youth or individual case examples of school-law enforcement crisis response models that were described, but not rigorously evaluated. It is apparent that there is a need for research investment in school mental health crisis response models to fill this gap. One of the largest such past investments in research identified in this review was the Safe Schools/Healthy Students initiative. This program was launched in 1999 as a collaboration between the US Departments of Health and Human Services, Justice, and Education to comprehensively address mental and emotional well-being and safety in schools (Derzon et al., 2012). However, evaluation of this program was challenged by the lack of a comparison group and data inconsistencies across schools. The results of the Safe Schools/Healthy Students evaluation also point to challenges with scaling local models or implementing successful models in different communities. Though it is clear that school-community partnerships are perceived by school staff as important to successful collaborations with law enforcement, there are challenges to scaling such localized models, and there is very limited evidence for whether school-law enforcement partnerships are useful for mental health crisis response.

\section{Discussion}

This systematic scoping review indicates that is a paucity of evidence-based models for law enforcement involvement in school mental health crisis response. Though in practice it is common for law enforcement officers to be involved in schools, primarily via a school resource officer model 
(Muller et al., 2021), and to respond to multiple kinds of student crises including mental health crises, this approach has yet to be rigorously evaluated. Contrary to this widely accepted model and generally favorable perceptions of law enforcement involvement in schools among White and suburban parents, research suggests that police contact with youth may have negative associations with mental and academic well-being and that policing may be disproportionately directed at racial and ethnic minority students (Jackson et al., 2019). Existing research on school-community partnerships does not consider the impacts of policing on students generally or the possibility of differential dynamics with or effects on racial or ethnic minority students. These findings raise concerns about the appropriateness of using a broad definition of "crisis" in schools that engages law enforcement officers in response to both violence against others and self-harm or suicidality. As such, it is essential for future research to assess how school-police partnerships might differentially impact racial or ethnic minority youth and to be cautious about generalizing "successful" partnership models across diverse communities. There is a need for research with racial/ethnic minority parents and students to understand a diversity of perspectives about the extent to which police presence in schools promotes safety.

Though existing models of mental health crisis response in schools involving police identified in our review were generally considered to be successful, there were significant methodological limitations to how these models were evaluated, raising further questions about the scalability of "successful" school-community partnerships involving law enforcement. One of the largest initiatives to address safety and mental health in schools, the Safe Schools/Healthy Students program, had modest success at the meta-analysis level, but methodological limitations to its evaluation approach do not allow us to draw conclusions about effective models and interventions for safety and mental health (Derzon et al., 2012). Despite these limitations, it is evident that school-community partnerships are critical to successfully engaging law enforcement officers in school. Crisis response models involving police identified in our review strongly emphasized relationship-building between law enforcement officers, students, and parents; a prevention and education role; and involving officers in student education (Daniels et al., 2007; Derzon et al., 2012; Heinen et al., 2006; James et al., 2011; Moriarty et al., 1993). These case reports are consistent with prior research indicating that strong schoolcommunity partnerships tend to be characterized by relationships among leaders, communication around barriers, commitment to quality improvement, and understanding the community and social context (Powers et al., 2013; Weist \& Evans, 2005; Weist et al., 2018).

School-community partnerships may be promising strategy for responding to mental health crises in schools, and such partnerships could extend beyond law enforcement alone to engage other community organizations and entities for crisis response (e.g., mental health). There is a defined model of school-community partnership typologies that includes the following, in order of increasing complexity: family and interagency collaborations, full-service schools, full-service community schools, and community development (Valli et al., 2016). The models identified in this review appear to fall into the first and second categories of schoolcommunity partnership, family and interagency collaboration and full-service schools. However, the partnerships are somewhat narrowly defined to be between schools and law enforcement only, with limited application of a partnership framework to other community entities. Additionally, the two more complex partnership categories which require greater shifts in school culture appear to have less of an evidence base. More specific research on the efficacy of schoollaw enforcement partnerships is needed, including efficacy for multiple kinds of crisis response and in response to different groups of students (e.g., racial/ethnic minorities and students with developmental disabilities). In settings where randomized controlled trials of law enforcement response models themselves are not feasible, schools may consider evaluating officer or teacher trainings or authoritative versus consultative roles for officers. Future research should also include comparative effectiveness studies of law enforcement partnerships for responding to mental health crisis versus mental health or other community partnerships. Such studies should take care to document not only efficacy for student and school outcomes (e.g., student and staff perceptions of safety, attendance, truancy, suspension, expulsion, injuries/assaults, academic outcomes), but partnership characteristics so that scalability and widespread implementation are possible.

\section{Limitations}

This review has several strengths and limitations that should be considered in interpreting its results. The specific search terms and inclusion criteria selected for the review may have limited articles using different definitions or terminology. Only studies taking place in the USA and published in English were included, limiting the cross-cultural implications of the findings. Our review did not prespecify a timeframe for the studies to be as inclusive as possible, but the societal perception of law enforcement has changed in recent years after high-profile police killings of unarmed Black men, women, and youth in the 2010s. This limits the applicability of earlier research to the current school context. There are strengths to this review as well. We used systematic methods to search a broad body of education, biomedical, and psychology literature. The results were verified by two independent reviewers. The inclusion criteria 
required data-based articles so that conclusions could be drawn based on empirical data rather than expert opinion or anecdotes. We identified methodological limitations to the studies using an established evidence rating system, allowing us both summarize findings and characterize the quality of scientific evidence.

\section{Conclusion}

In a context of reflection on the role of law enforcement officers in society and communities, it is essential to consider how schools fit in. The school resource officer model is widely used for responding to many kinds of student crises, including mental health crises, but this model has not been empirically evaluated to assess its impact on student mental health. This scoping review suggests that more research is needed on how police involvement in school mental health crises affects youth mental health outcomes. It also suggests that school-community partnerships hold promise for managing mental health crises in schools, and partnership models for crisis response need not be narrowly defined to partnerships with law enforcement alone. In the absence of empirical evidence supporting the use of current models, there is a need for research on law enforcement involvement in school crisis response and, more broadly, innovative, community-partnered models of responding to student mental health needs.

Supplementary Information The online version contains supplementary material available at https://doi.org/10.1007/s12310-021-09477-z.

Acknowledgements Dr. Choi acknowledges K12 career development award support (K12HS26407-01) from the Agency for Healthcare Research and Quality (AHRQ) and the Patient-Centered Outcomes Research Institute (PCORI). The award was provided through the Stakeholder-Partnered Implementation Research and Innovation Translation (SPIRIT) Program at UCLA and Kaiser Permanente Southern California. Dr. Ijadi-Maghsoodi receives funding from the National Institute on Drug Abuse of the National Institutes of Health under Award Number K12DA000357. Dr. Zima receives research funding from the Mental Health Services Oversight and Accountability Commission (SB 82) and the Substance Abuse Mental Health Services Administration. The views expressed in this article are those of the authors. The contents of this article do not represent the views of the U.S. Department of Veterans Affairs or the United States Government.

Funding No funding is associated with this review article.

Availability of Data and Material The literature table containing data presented in this article is included as Supplemental Digital Content.

\section{Declarations}

Conflict of interest The authors declare that they have no conflicts of interest.
Open Access This article is licensed under a Creative Commons Attribution 4.0 International License, which permits use, sharing, adaptation, distribution and reproduction in any medium or format, as long as you give appropriate credit to the original author(s) and the source, provide a link to the Creative Commons licence, and indicate if changes were made. The images or other third party material in this article are included in the article's Creative Commons licence, unless indicated otherwise in a credit line to the material. If material is not included in the article's Creative Commons licence and your intended use is not permitted by statutory regulation or exceeds the permitted use, you will need to obtain permission directly from the copyright holder. To view a copy of this licence, visit http://creativecommons.org/licenses/by/4.0/.

\section{References}

Albright, K., Barnard, J., O’Leary, S., Federico, S., Saville, A., Lockhart, S., Lee, M., Eblovi, D., Dickinson, M., Kile, D., \& Kempe, A. (2016). School-based health centers as medical homes: Parents' and adolescents' perspectives. Academic Pediatrics, 16(4), 381-386. https://doi.org/10.1016/j.acap.2015.06.004

Allen, T., Bryan, I., Guererro, A., Teng, A., Lytle-Hernandez, K., \& Million Dollar Hoods. (2018). Policing our students: An analysis of LA school police department data (2014-2017). http://milli ondollarhoods.org/wp-content/uploads/2018/10/Policing-OurStudents-MDH-Report-Final.pdf.

Amaral, G., Geierstanger, S., Soleimanpour, S., \& Brindis, C. (2011). Mental health characteristics and health-seeking behaviors of adolescent school-based health center users and nonusers. Journal of School Health, 81(3), 138-145. https://doi.org/10.1111/j. 1746-1561.2010.00572.x

Anderson-Butcher, D., Stetler, E. G., \& Midle, T. (2006). School-community partnerships in support of positive youth development: A case for expanded school-community partnerships in support of positive youth development. Children \& Schools, 28(3), 155-163.

Arksey, H., \& O'Malley, L. (2005). Scoping studies: Towards a methodological framework. International Journal of Social Research Methodology, 8(1), 19-32. https://doi.org/10.1080/1364557032 000119616

Barnes, J., \& Motz, R. (2018). Reducing racial inequalities in adulthood arrest by reducing inequalities in school discipline: Evidence from the school-to-prison pipeline. Developmental Psychology, 54(12), 2328. https://psycnet.apa.org/record/2018-47616-001.

Centers for Disease Control and Prevention. (2021). Suicide prevention: Fast facts. https://www.cdc.gov/suicide/facts/index.html.

Children's Civil Commitment and Mental Health Treatment Act of 1988. (1988). Pub. L. No. Division 5, Part 1.5.

Daniels, J. A., Bradley, M. C., Cramer, D. P., Winkler, A. J., Kinebrew, K., \& Crockett, D. (2007). The successful resolution of armed hostage/barricade events in schools: A qualitative analysis. Psychology in the Schools, 44(6), 601-613. https://doi.org/10.1002/ pits. 20250

Del Toro, J., Lloyd, T., Buchanan, K. S., Robins, S. J., Zhang Bencharit, L., Gamson Smiedt, M., Reddy, K. S., Rodriguez Pouget, E., Kerrison, E. M., \& Goff, P. A. (2019). The criminogenic and psychological effects of police stops on adolescent Black and Latino boys. PNAS, 116(17), 8261-8268. https://doi.org/10.1073/ pnas. 1808976116

Derzon, J. H., Yu, P., Ellis, B., Xiong, S., Arroyo, C., Mannix, D., Wells, M. E., Hill, G., \& Rollison, J. (2012). A national evaluation of safe schools/healthy students initiative: Outcomes and influences. Evaluation and Program Planning, 35, 293-302.

DeVane, S. (1996). Student discipline: A school district's response to SAFE schools. Thresholds in Education, 22(4), 17-20. 
Diliberti, M., Jackson, M., Correa, S., \& Hansen, R. (2017). Crime, violence, discipline, and safety in U.S. public schools: Findings from the School Survey on Crime and Safety: 2017-18. https:// nces.ed.gov/pubs2019/2019061.pdf.

Dreyer, B. P., Trent, M., Anderson, A., Askew, G. L., Boyd, R., Coker, T. R., Coyne-Beasley, T., Fuentes-Afflick, E., Johnson, T., Mendoza, F., Montoya-Williams, D., Oyeku, S., Poitevien, P., SpinksFranklin, A. A. I., Thomas, O. W., Walker-Harding, L., Willis, E., Wright, J., Berman, S., ... Stein, F. (2020). The death of George Floyd: Bending the arc of history towards justice for generations of children. Pediatrics. https://doi.org/10.1542/peds.2020-009639.

Ehrenfeld, J. M., \& Harris, P. A. (2020). Police brutality must stop. AMA Leadership. https://www.ama-assn.org/about/leadership/ police-brutality-must-stop?utm_campaign=meetedgar\&utm_ medium $=$ social\&utm_source $=$ meetedgar.com.

Eklund, K., Meyer, L., \& Bosworth, K. (2018). Examining the role of school resource officers on school safety and crisis response teams. Journal of School Violence, 17(2), 139-151. https://doi. org/10.1080/15388220.2016.1263797

Engel, R. S., McManus, H. D., \& Herold, T. D. (2020). Does de-escalation training work? Criminology \& Public Policy, 19(3), 721-759. https://doi.org/10.1111/1745-9133.12467

Farmer, E. M. Z., Burns, B. J., Phillips, S. D., Angold, A., \& Costello, E. J. (2003). Pathways into and through mental health services for children and adolescents. Psychiatric Services, 54(1), 60-66.

Fine, A. D., Kan, E., \& Cauffman, E. (2019). Adolescents' confidence in institutions: Do America's youth differentiate between legal and social institutions? Developmental Psychology, 55(8), 1758-1767. https://doi.org/10.1037/dev0000760

Ghandour, R. M., Sherman, L. J., Vladutiu, C. J., Ali, M. M., Lynch, S. E., Bitsko, R. H., \& Blumberg, S. J. (2019). Prevalence and treatment of depression, anxiety, and conduct problems in US children. Journal of Pediatrics, 206, 256-267.e3. https://doi.org/ 10.1016/j.jpeds.2018.09.021

Gomez, M. (2021b, July). Pomona school district defunds police, reimagines school safety. Los Angeles Times.

Gomez, M. (2021a). L.A. school board cuts its police force and diverts funds for Black student achievement. Los Angeles Times.

Gottlieb, A., \& Wilson, R. (2019). The effect of direct and vicarious police contact on the educational achievement of urban teens. Children and Youth Services Review, 103, 190-199. https://doi. org/10.1016/j.childyouth.2019.06.009

Green, J. G., McLaughlin, K. A., Alegria, M., Costello, E. J., Gruber, M. J., Hoagwood, K., Leaf, P. J., Olin, S., Sampson, N. A., \& Kessler, R. C. (2013). School mental health resources and adolescent mental health service use. Journal of the American Academy of Child \& Adolescent Psychiatry, 52(5), 501-510.

Heinen, E., Webb-Dempsey, J., Moore, L. C., Mcclellan, C. S., \& Friebel, C. H. (2006). Implementing district safety standards at the site level. NASSP Bulletin, 90(3), 207-220. https://doi.org/10.1177/ 0192636506291589

Jackson, D. B., Fahmy, C., Vaughn, M. G., \& Testa, A. (2019). Police stops among at-risk youth: Repercussions for mental health. Journal of Adolescent Health, 65(5), 627-632. https://doi.org/ 10.1016/j.jadohealth.2019.05.027

Jahn, J. L., Agenor, M., Chen, J. T., \& Krieger, N. (2020). Frequent police stops, parental incarceration and mental health: Results among US non-Hispanic Black and White adolescent girls and boys. Journal of Epidemiology and Community Health, 0, 1-7. https://doi.org/10.1136/jech-2020-214578

James, R. K., Logan, J., \& Davis, S. A. (2011). Including school resource officers in school-based crisis intervention: Strengthening student support. School Psychology International, 32(2), 210-224. https://doi.org/10.1177/0143034311400828

Kerr, M. M., \& King, G. (Eds.). (2018). School crisis prevention and intervention (2nd ed.). Waveland Press, Inc.
Krezmien, M. P., Leone, P. E., \& Achilles, G. M. (2006). Suspension, race, and disability: Analysis of statewide practices and reporting. Journal of Emotional and Behavioral Disorders, 14(4), 217-226.

Merikangas, K. R., He, J., Burstein, M., Swanson, S. A., Avenevoli, S., Cui, L., Benjet, C., Georgiades, K., \& Swendson, J. (2010). Lifetime prevalence of mental disorders in U.S. adolescents: Results from the National Comorbidity Survey Replication-Adolescent Supplement (NCS-A). Journal of the American Academy of Child \& Adolescent Psychiatry, 49(10), 980-989.

Moher, D., Liberati, A., Tetzlaff, J., \& Altman, D. G. (2009). Preferred reporting items for systematic reviews and meta-analyses: The PRISMA statement. PLoS Medicine, 6(7), e1000097. https://doi. org/10.1371/journal.pmed.1000097

Moriarty, A., Maeyama, R. G., \& Fitzgerald, P. J. (1993). A CLEAR plan for school crisis management. NASSP Bulletin, 17-22.

Muller, R., Morabito, M. S., \& Green, J. G. (2021). Police and mental health in elementary and secondary schools: A systematic review of the literature and implications for nursing. Journal of Psychiatric and Mental Health Nursing, 28(1), 72-82. https://doi.org/ 10.1111/jpm. 12704

Nickerson, A. B., \& Martens, M. P. (2008). School violence: Associations with control, security/enforcement, educational/therapeutic approaches, and demographic factors. School Psychology Review, 37(2), 228-243. https://doi.org/10.1080/02796015.2008.12087 897

Oxford Centre for Evidence-Based Medicine. (2009). Levels of evidence. https://www.cebm.ox.ac.uk/resources/levels-of-evide nce/oxford-centre-for-evidence-based-medicine-levels-of-evide nce-march-2009.

Payton, E., Khubchandani, J., Amy, T., \& Price, J. H. (2017). Parents' expectations of high schools in firearm violence prevention. Journal of Community Health, 42, 1118-1126. https://doi.org/10.1007/ s10900-017-0360-5

Pham, M. T., Rajić, A., Greig, J. D., Sargeant, J. M., Papadopoulos, A., $\&$ McEwen, S. A. (2014). A scoping review of scoping reviews: Advancing the approach and enhancing the consistency. Research Synthesis Methods, 5(4), 371-385. https://doi.org/10.1002/jrsm. 1123

Powers, J. D., Edwards, J. D., Blackman, K. F., \& Wegmann, K. M. (2013). Key elements of a successful multi-system collaboration for school-based mental health: In-depth interviews with district and agency administrators. Issues and Ideas in Public Education, 5(4), 651-670. https://doi.org/10.1007/s11256-013-0239-4

Rocque, M., \& Paternoster, R. (2011). Understanding the antecedents of the "school-to-jail" link: The relationship between race and school discipline. Journal of Criminal Law and Criminology, 101(2), 633-665. https://www.jstor.org/stable/pdf/23074048.pdf

Seo, C., Kim, B., \& Kruis, N. E. (2021). Variation across police response models for handling encounters with people with mental illnesses: A systematic review and meta-analysis. Journal of Criminal Justice, 72, 101752. https://doi.org/10.1016/j.jcrimjus. 2020.101752

Swartz, T. (2021). More Chicago high schools vote to remove school police. Chicago Tribune.

Turner, E. O., \& Beneke, A. J. (2019). Race ethnicity and education "softening" school resource officers: The extension of police presence in schools in an era of Black Lives Matter, school shootings, and rising inequality. Race Ethnicity and Education, 23(2), 221-240. https://doi.org/10.1080/13613324.2019.1679753

Turney, K. (2020). Depressive symptoms among adolescents exposed to personal and vicarious police contact. Society and Mental Health, 00, 1-21. https://doi.org/10.1177/2156869320923095

Valli, L., Stefanski, A., \& Jacobson, R. (2016). Typologizing schoolcommunity partnerships: A framework for analysis and action. Urban Education, 51(7), 719-747. https://doi.org/10.1177/00420 85914549366 
Walters, A. S. (2020). The role of police in public schools: Harmful or helpful? The Brown University Child and Adolescent Behavior Letter, 36(10), 8-8. https://doi.org/10.1002/cbl.30497

Weist, M. D., Eber, L., Horner, R., Splett, J., Putnam, R., Barrett, S., Perales, K., Fairchild, A. J., \& Hoover, S. (2018). Improving multitiered systems of support for students with "internalizing" emotional/behavioral problems. Journal of Positive Behavior Intervention, 20(3), 172-184.

Weist, M. D., \& Evans, S. W. (2005). Expanded school mental health: Challenges and opportunities in an emerging field. Journal of Youth and Adolescence, 34(1), 3-6. https://doi.org/10.1007/ s10964-005-1330-2

Welch, K., \& Payne, A. A. (2010). Racial threat and punitive school discipline. Social Problems, 57(1), 1533-8533. https://doi.org/10. 1525/sp.2010.57.1.25
Werlen, L., Gjukaj, D., Mohler-Kuo, M., \& Puhan, M. A. (2020). Epidemiology and psychiatric sciences interventions to improve children's access to mental health care: A systematic review and meta-analysis. Epidemiology and Psychiatric Sciences, 29(e58), 1-27. https://doi.org/10.1017/S2045796019000544

Publisher's Note Springer Nature remains neutral with regard to jurisdictional claims in published maps and institutional affiliations. 